\title{
Non-Radiological Progression
}

National Cancer Institute

\section{Source}

National Cancer Institute. Non-Radiological Progression. NCI Thesaurus. Code C96608.

A non-radiological determination of disease progression based on symptoms or other findings. 